\title{
TENDÊNCIAS DE DESIGN PARA SITES DE MARCAS DO MERCADO DA MODA
}

\author{
DESIGN TRENDS FOR FASHION MARKET WEBSITES
}

\author{
Talita de Oliveira Scutare - talita.scutare@gmail.com \\ Gustavo Henrique Del Vechio - gustavo.vechio@ fatectq.edu.br \\ Faculdade de Tecnologia de Taquaritinga (FATEC) -SP -Brasil \\ DOI: 10.31510/infa.v16i2.661
}

\begin{abstract}
RESUMO
Projetar layouts de sites da web não é apenas uma questão de pensar em beleza ou estética. Mais do que isso, é preciso planejar cuidadosamente cada elemento visual, tendo em vista sua função ou sua contribuição para garantir uma ótima experiência de navegação, ao mesmo tempo em que apresenta, com clareza, o conteúdo de cada página. Posto dessa forma, este estudo procura avaliar como o design de página, por meio de geometrias, imagens, cores e tipos de texto combinam-se a fim de garantir uma boa percepção visual, enquanto destaca a marca e o conteúdo projetado para cada página. Neste caso, deseja-se analisar, mais especificamente, as marcas do segmento da moda (de luxo), a fim de compreender melhor certas tendências quanto à projeção de seus layouts. Entender, afinal, como as marcas mais famosas neste segmento projetam seus layouts pode ser muito útil para outras marcas se inspirarem e caminharem na mesma direção. A constatação deste estudo é que um design minimalista, que está menos preocupado em detalhes ou efeitos para o layout e mais focalizado na exibição imagética das peças e itens de moda, é muito mais vantajoso para destacar os modelos e coleções, que se renovam frequentemente e precisam chamar a atenção daqueles que se interessam em acompanhar ou estar sempre atualizados com a moda.
\end{abstract}

Palavras-chave: Design. Layout. Website. Moda. Luxo.

\begin{abstract}
Designing website layouts is not just a matter of thinking about beauty or aesthetics. More than that, its necessary to carefully plan each visual element for its function or contribution to ensure a great browsing experience, while clearly presenting the content of each page. This study seeks to evaluate how page design through geometries, images, colors, and text types combine to ensure good visual perception, while highlighting the brand and content designed for each page. In this case, it analyzes, more specifically, the luxury brands, in order to better understand certain trends regarding the design of their layouts. Understanding, after all, how the most famous brands in this segment design their layouts can be very helpful for other brands to be inspired and to move in the same direction. The finding of this study is that a minimalist design, which is less concerned with details or effects for the layout and more focused on the imagery display of fashion pieces and items, is much more advantageous to highlight the frequently renewed models and collections and need to catch the eye of those who are interested in keeping up with or always up to date with fashion.
\end{abstract}

Keywords: Design. Layout Website. Fashion. Lux. 


\section{INTRODUÇÃO}

O design é um campo de estudos de imensas aplicações, capaz de dialogar com as mais diferentes áreas do conhecimento. Da arquitetura à engenharia, do desenvolvimento de produtos à sistemas, da moda à ilustração, há sempre espaço para se pensar em design. Isto porque o design, como argumenta Wollner (apud STOLARSKI, 2005, p. 67), não se restringe apenas aos propósitos de beleza, estética e emoção, como muitos podem imaginar. Embora estes critérios sejam, de fato, importantíssimos, em suas concepções mais profundas o design refere-se ao desenvolvimento de um projeto eficiente, elaborado para as necessidades daqueles que um dia devem utilizá-lo. Ou seja, o design é uma área tanto projetual quanto informacional, que influi na valorização das experiências e que é, portanto, "dedicado à objetivação, à construção e à materialização de ideias” (CARDOSO, 2013, p. 246).

Levando-se este conceito ao universo digital, mais especificamente ao planejamento e desenvolvimento de sites para a web, o design não trata apenas de criar belas páginas que são ricas visualmente. Ora, não adianta uma página ser belíssima, mas precária em termos de navegação e acesso à informação; ou, ainda, ter um visual realmente exuberante, mas aqueles que a acessam demoram tempo demais para encontrarem aquilo de que procuram.

Cada elemento inserido em um projeto deve ser pensado, portanto, quanto ao seu propósito, isto é, sua função, além de sua contribuição visual. Por exemplo, Lupton e Phillips (2015, p. 33-38) destacam que pontos, linhas e planos são essenciais ao design, pois alicerçam a criação de imagens, ícones, texturas, ilustrações, vídeos, animações e até sistemas tipográficos. De fato, é claro que uma linha horizontal pode muito bem dar um toque de beleza no visual da página; no entanto, ela pode ser muito mais do que isso: pensada em termos de design e função, a linha pode indicar a divisão entre áreas visuais e até guiar os olhos do observador a regiões consideradas importantes dentro da composição.

Wollner (apud STOLARSKI, 2005, p. 66) revela que não consegue estudar ou ler, por muito tempo, um texto que seja escrito por uma fonte sem serifas, já que esse tipo de fonte cansa a vista rapidamente. A lição, neste caso, é que pensar somente no texto em si, deixando de lado aspectos do seu design, pode comprometer e tornar precária a experiência de lê-lo.

$\mathrm{O}$ que estes dois exemplos demonstram é que o design, mais do que envolver o público e encantá-lo visualmente, deve ser encarado como um projeto em que cada elemento é pensado para ter uma função. Como explica Wollner (apud STOLARSKI, 2005, p. 68), o 
design se relaciona não apenas à criatividade, mas à tecnologia, ao significado e à linguagem. Ou, como complementam Lupton e Philips (2015, p. 14), é por meio de um design impecável e bem pensado que as experiências podem realmente se tornar mais prazerosas.

Sob essa perspectiva, este estudo tem o objetivo de analisar como certos elementos de design, tais como cores, linhas, pontos, imagens, ilustrações e textos aplicam-se na construção de sites da web. Para essa análise, optou-se intencionalmente por escolher alguns sites de marcas do segmento da moda, tendo em vista que este é um mercado que lida frequentemente com os fundamentos do design em seus itens. Como observa Oliveira (2007, p.37), a moda se apoia em linhas, formas, cores, texturas e pontos para seus cortes, decotes e bordados, sendo necessário articular cores, dimensões com formas e as mais variadas combinações quanto às linhas, retas horizontais, verticais, diagonais ou curvas diversas.

Assim, a pergunta que norteia esta pesquisa é: como é que marcas conceituadas do segmento de moda, que se preocupam tanto com o design de seus itens de vestuário, projetam e pensam no design em seus sites institucionais?

A hipótese é de que, assim como é possível observar diversas tendências quanto ao desenvolvimento das peças de moda, também os sites das marcas conceituadas deste segmento podem apresentar similaridades que permitam indicar certas tendências quanto ao design das suas páginas da web. É, assim, aliás, que o estudo se justifica: se for possível encontrar semelhanças entre as páginas, pode-se, por consequência, apontar certas concretudes em relação ao design de páginas web voltadas para a área da moda.

\section{FUNDAMENTAÇÃO TEÓRICA}

A Internet jamais teria alcançado tamanha repercussão e quantidade de usuários se não fossem as interfaces gráficas que dão sustentação à World Wide Web. Por mais que alguém consiga acessar a rede por meio de linguagens de programação, são poucos aqueles que o fazem desta forma. Para a grande maioria dos internautas, o contato com as páginas se dá por meio de alguma configuração visual e aparência ininteligível (CARDOSO, 2013, p. 207).

Mesmo a web sendo relativamente nova em comparação a meios como jornal, rádio e televisão, Cardoso (2013, p. 208) verifica que já é possível identificar arquétipos e apontar tendências quanto ao design das páginas. Os grandes sites de notícia e comércio, por exemplo, 
tendem a seguir formas mais ou menos similares, com cabeçalhos, rodapés, menus e divisões de layout estruturados e posicionados de formas mais ou menos equivalentes:

\begin{abstract}
Muitas páginas no ambiente virtual obedecem a uma configuração próxima à de uma primeira página de jornal: cabeçalho ao topo; organização da informação em colunas e blocos; emprego de títulos acima dos textos e de legendas abaixo das imagens; presença de índice, sumário ou outro sistema de remissão à parte "interna". Outras páginas - em especial, as de comércio eletrônico - possuem semelhanças com a estrutura visual de um catálogo de vendas, ou seja: o posicionamento das imagens em colunas e fileiras regulares, criando uma estrutura de equivalência e comparação entre os itens representados. Os modelos diagramáticos são diversos, com paralelos a outras modalidades históricas de impressos, tais quais revistas, livros, folhetos, e assim por diante (CARDOSO, 2013, p. 209).
\end{abstract}

No desenvolvimento de páginas web, diversos tipos de elementos podem contribuir para se obter um design que é, ao mesmo tempo, elegante e eficiente do ponto de vista da navegação e do acesso à informação. Tanto Ambrose e Harris (2012) quanto Lupton e Phillips (2015) citam, com grande ênfase, a importância das geometrias (incluindo pontos, linhas e planos), das ilustrações e imagens fotográficas, das cores e dos tipos de texto. Há, ainda, que se considerar os princípios que definem ou combinam estes elementos, tais como os conceitos de simetria e assimetria, grades, equilíbrio, contraste, proximidade, semelhança, harmonia, pregnância e muitos outros, quais sejam os princípios do Gestalt ${ }^{1}$ (GOMES FILHO, 2009). Embora tais princípios não sejam exatamente o foco deste estudo, frequentemente eles são utilizados em páginas para obter relações visuais entre os elementos de design.

Antes, porém, de verificar como cores, geometrias, imagens e tipos aplicam-se em sites de marcas da indústria da moda, convém fazer uma breve descrição sobre estes elementos, a fim de compreender por que eles são pertinentes em um design.

\title{
2.1 Geometrias: pontos, linhas e planos
}

Tudo o que se vê possui uma forma, escreve Gomes Filho (2009, p. 41). As formas são geradas a partir de primitivas geométricas, como pontos, linhas e planos. Enquanto o ponto indica uma posição no espaço, por meio de coordenadas x e y, a linha corresponde à conexão entre dois pontos ou, ainda, o trajeto de um ponto em movimento. É, por conseguinte, a junção de linhas que formam os planos (LUPTON; PHILLIPS, 2015, p. 33-38).

\footnotetext{
${ }^{1}$ O Gestalt, de acordo com Gomes Filho (2009, p. 18) refere-se ao conceito de que a integração das partes acaba por ser maior do que a soma do todo.
} 
Embora pontos e linhas sejam formas geométricas primitivas, elas podem ser muito importantes em um design de página para indicar divisões, apontar áreas importantes, bem como guiar o olhar à uma direção que se queira. Utilizados cuidadosamente, estes elementos tornam-se essenciais para a interpretação visual e a compreensão de um layout.

\subsection{Imagens fotográficas e ilustrações}

Pontos, linhas e planos também são a base para a geração de ilustrações, assim como estão presentes em fotografias. No ambiente digital, as imagens podem ser geradas ou a partir de uma grade de pontos, chamados por pixels (tecnologia raster), ou por meio da interação entre pontos e linhas (vetores) calculados matematicamente (tecnologia vetorial). Ambas as tecnologias possuem vantagens e desvantagens e podem, inclusive, ser combinadas na mesma composição, o que significa que não elas são excludentes (DEL VECHIO, 2012, p. 2-18).

Para Ambrose e Harris (2012, p. 94), as imagens são comunicadores poderosos justamente pelos significados emocionais, culturais e factuais que carregam. O modo como as imagens são apresentadas pode afetar o observador de diversas maneiras, tanto positiva quanto negativamente: uma fotografia é, assim, mais do que a captura de um instante ou de um período no espaço-tempo (neste caso, um vídeo), assim como uma ilustração é mais do que a composição de primitivas geométricas arranjadas propositalmente. As imagens carregam significados que se transformam em conceitos na mente daqueles que as observam.

\subsection{Cores}

Tecnicamente, cores são ondas eletromagnéticas dispersadas por uma origem de luz, interagem com o ambiente, alcançam os olhos do observador e são, enfim, decodificadas pela mente. São, em outras palavras, "uma informação visual, causada por um estímulo físico, percebida pelos olhos e decodificada pelo cérebro" (GUIMARÃES, 2004, p. 12).

Claro que, ao analisar a cor a partir da física, da química e da biologia, verifica-se o papel fundamental da origem da luz, dos objetos e do observador que enxerga o mundo ao seu redor (DEL VECHIO, 2015, p. 115). No entanto, em termos de design e comunicação, a cor é, fundamentalmente, portadora de significados, ou, como diz Guimarães (2004, p. 16), trata-se de um elemento da sintaxe da linguagem visual. As cores provocam estímulos e reações e 


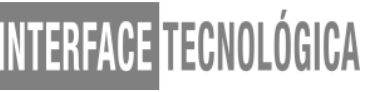

acabam por se associarem a ideias, lembranças e sensações. As combinações de cores podem remeter, por exemplo, à infância, transmitirem alegria ou tristeza, sofisticação, modernidade ou antiguidade, parecerem dinâmicas ou estáticas, entre outros (MESTRINER, 2005, p. 53). Como complementa Heller (2013, p.17): "cores e sentimentos não se combinam ao acaso nem são uma questão de gosto individual - são vivências comuns que, desde a infância, foram ficando profundamente enraizadas em nossa linguagem e em nosso pensamento."

Logo, a utilização de cores em projetos de design, incluindo as páginas para web, não deve ser alicerçada em gostos pessoais ou meras escolhas irrefletidas de tons harmônicos; deve, ao contrário, ser planejada para transmitir um significado e evocar sensações.

\subsection{Tipos de texto}

Das fontes serifas às sem serifa, das artísticas e ornamentadas às mais concisas, das clássicas às modernas, há inúmeras fontes disponíveis para a exibição de textos no universo digital. A tipografia, dizem Ambrose e Harris (2012, p. 55), é o meio pelo qual uma escrita recebe forma visual, fazendo com que o texto seja exibido naturalmente ao leitor.

Claro que a interpretação de cada indivíduo é sempre subjetiva; no entanto, assim como nas cores, os tipos carregam um significado e podem despertar paixões, simbolizar movimentos, exprimir personalidades e muito mais (AMBROSE; HARRIS, 2012, p. 55). Uma boa escolha tipográfica para uma página, portanto, é essencial tanto para transmitir um significado quanto para garantir a boa leitura: não é surpresa Wollner (apud STOLARSKI, 2005, p. 66), assim como Malzone (2012, p. 298-299), notarem que a escolha de tipos (bem como seus parâmetros, tais como tamanho da fonte, espaço entrelinhas e outros) influencia diretamente no fluxo da leitura, podendo torná-lo mais cansativo ou menos prazeroso.

\section{PROCEDIMENTOS METODOLÓGICOS}

Realizada uma breve descrição quanto a pertinência de geometrias, imagens, cores e tipos no planejamento e desenvolvimento de um bom layout, pode-se agora avançar o estudo a fim de avaliar como diferentes sites utilizam estes elementos em seus projetos, na tentativa de se conectarem emocionalmente aos indivíduos e transmitirem a eles um significado. 


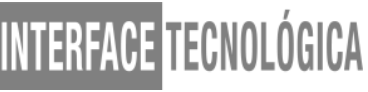

Para isso, propõe-se uma análise comparativa entre 10 sites institucionais de marcas conhecidas do segmento da moda. A razão pela qual este segmento é escolhido diz respeito ao fato de que, na moda, há uma enorme preocupação quanto ao design das peças e seus significados; logo, seus sites deveriam estar à altura destes bens de consumo.

Já a escolha das 10 marcas é intencional, tendo em vista as 10 marcas de luxo mais valiosas de 2019, segundo o estudo "BrandZ Top Global Brands", da Kantar Millward Brown (vide https://bit.ly/2X0olex). São elas: (1) Louis Vuitton; (2) Chanel; (3) Hermès; (4) Gucci; (5) Rolex; (6) Cartier; (7) Burberry; (8) Dior; (9) Yves Saint Laurent; (10) Prada.

Os seguintes critérios serão analisados entre estes sites: (1) uso de geometrias e ilustrações; (2) uso de fotografias e vídeos; (3) uso de cores; (4) uso de tipos de texto. Com essas análises, espera-se encontrar certas similaridades que permitam compreender melhor como o design de sites de moda geralmente são elaborados.

\section{RESULTADOS E DISCUSSÕES}

\subsection{Geometrias e ilustrações}

Uma análise atenta sobre os sites das 10 marcas mais valiosas do mundo no segmento da moda (marcas de luxo), permite a constatação de que suas páginas não apresentam o uso demasiado de geometrias e ilustrações, exceto para as linhas, pontos e traços que fazem parte do layout, a fim de dividir os elementos visuais e guiar o olhar a áreas específicas de caixas de texto e fotos. A figura a seguir demonstra, como exemplo, os sites da Cartier e Gucci.

Figura 1. Arranjo de layout nos sites Cartier e Gucci (exemplo da página inicial)
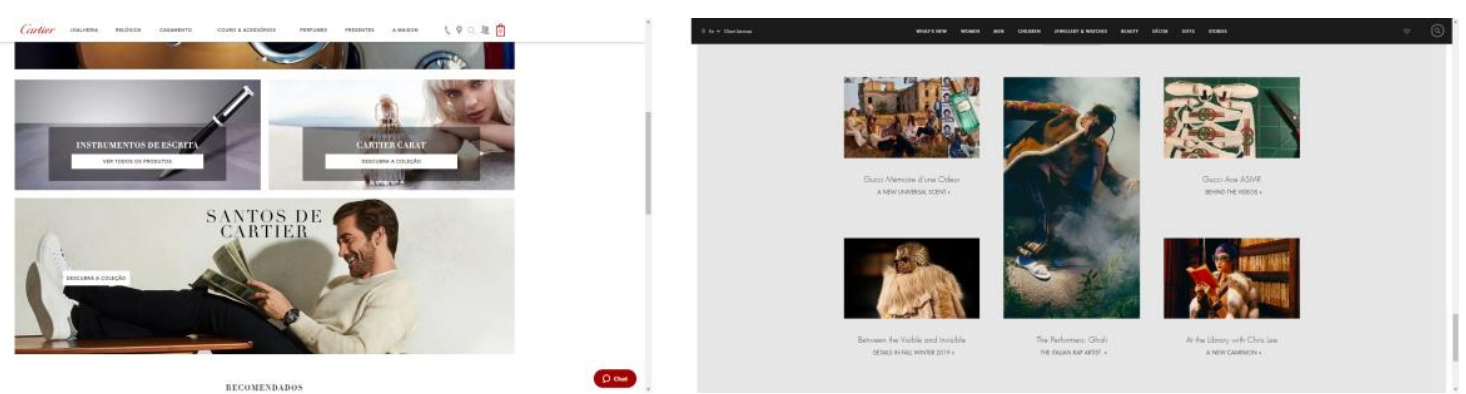

Fonte: capturas de tela realizadas pelos autores. 
Todas marcas, como se poderia esperar, deixam em realce seu logo, sobretudo na primeira página do site. No entanto, raramente é observável o uso de outros tipos de ilustrações representativas (signos). Quanto aos ícones, embora existam pequenas variações em cada site, é notável o fato de todas elas carregarem um campo de pesquisa com o ícone de uma lupa, bem como o ícone de um carrinho de compras para aqueles que desejam realizar aquisições. Ao que parece, também é comum estes sites utilizarem o ícone de um coração para permitir aos usuários opinarem quanto as peças ou coleções favoritas, o que ajuda a selecionar itens, compartilhá-los ou voltar a acessá-los para obter mais informações.

Todos os sites analisados também trazem os ícones representativos das redes sociais mais populares da atualidade, tais como o Facebook e o Instagram, embora estes logos sejam geralmente apresentados em apenas 1 cor, na maioria das vezes branco, preto ou cinza. A presença destas marcas nas redes sociais é muito importante porque contribui para a interatividade e para o contato mais próximo com o público de interesse.

\subsection{Fotografias e vídeos}

Tendo em vista que o segmento de moda se aproveita do alto impacto visual para ofertar ou comercializar seus itens de vestuário, não é surpresa que todos os sites façam uso demasiado de muitas fotos, bem como alguns deles também apresentam vídeos em suas principais páginas. Para ser mais preciso, 4 entre os 10 sites analisados fazem uso de vídeos, sendo tais produções relacionados comumente a desfiles, ensaios fotográficos ou eventos de moda mundialmente conhecidos. Nunca se pode esquecer, afinal, a importância dos desfiles para este segmento, cuja cobertura midiática é de fundamental importância.

Muitos sites visitados na web, dos mais diferentes segmentos, possuem, geralmente na página inicial, um slide-show (ou "carrossel", como se queira chamar) para destacar certos produtos, serviços, promoções ou acontecimentos. Mas, entre os 10 sites do segmento da moda analisados, observa-se que apenas a metade se aproveita deste recurso. Aqui vale um destaque para os sites das marcas Rolex e Prada, que intercalam o uso de imagens e vídeos no carrossel, o que certamente agrega em destaque visual para suas páginas. 
Figura 2. Página inicial dos sites da Rolex e da Prada
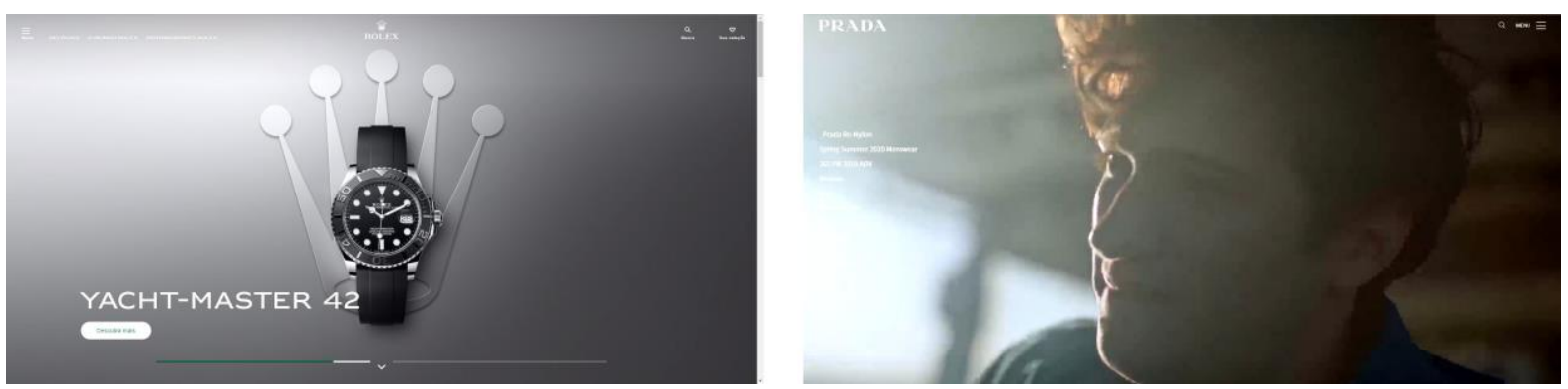

Fonte: capturas de tela realizadas pelos autores.

Seja como for, em todos os sites nota-se claramente a preocupação com fotografias e vídeos de alta qualidade, não apenas quanto a resolução de pixels, mas também com relação aos cuidados com iluminação, ângulo, contraste de cores e outros aspectos.

Vale destacar, ainda, que cada coleção de moda é baseada em uma determinada história e esse aspecto fica muito evidente nas fotos publicitárias dessas coleções. Em outras palavras, as imagens refletem essa essência: não é preciso um texto explicativo ou um narrador para compreender a história que serve de inspiração para cada coleção ou peça.

\subsection{Cores}

Definitivamente, o preto e o branco são os tons de mais alto contraste que se pode ter. Entre as marcas da moda, ambas são frequentemente utilizadas em conjunto, porém seu uso diferente com relação a importância para cada layout. Para se ter ideia, o preto nem sempre é usado demasiadamente para representar luxo. Dos 10 sites analisados neste estudo, 8 fazem o uso do branco como sua cor principal, mantendo o preto para destacar certos detalhes, bem como compor o rodapé. Mesmo alguns sites, tais como o da Gucci (vide figura 1), que prefere a predominância do cinza, ou o site da Hèrmes, que faz uso considerável de um tom de rosa (figura 3), preferem, essencialmente, o uso de cores claras. Uma explicação para essa tendência é que o branco ou as cores mais claras possibilitam que haja bastante contraste com as próprias peças de vestuário exibidas em cada página. 


\section{NTEREFACE TECNOLOLGCA}

Figura 3. Página inicial do site da Hèrmes, em tons rose.

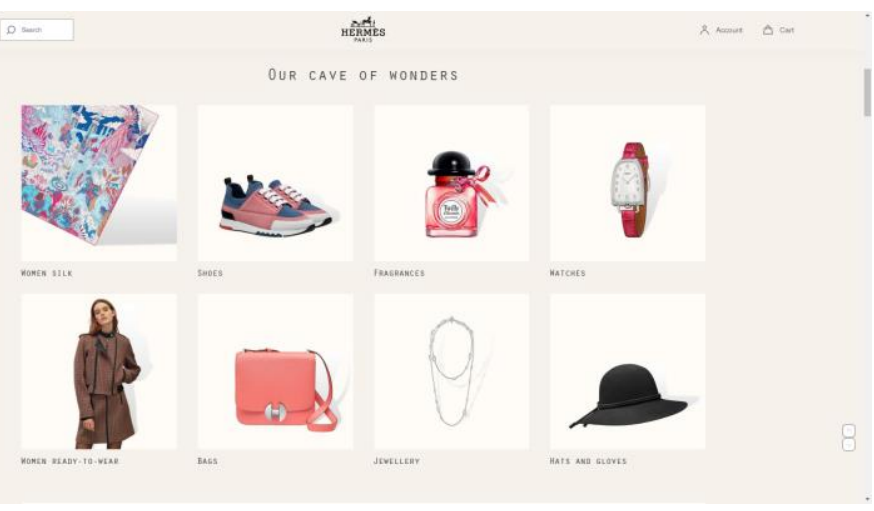

Fonte: captura de tela realizada pelos autores.

Adicionalmente, também não se pode esquecer que as cores fazem parte da identidade visual de cada marca; logo, a escolha de cores, tanto em sites quanto em quaisquer outras manifestações da marca (lojas físicas, cartões, uniformes, veículos, etc) não é e nem deveria ser arbitrária; pelo contrário, as cores acabam por refletir a marca e seus valores, o que significa que as sutis variações entre cada site analisado, em termos de cores, devem-se pelo fato de haver essa ligação direta com o projeto de sentidos de cada marca.

Um outro aspecto observável nos sites analisados é que a predominância está nos tons sólidos em vez de gradiente de cores, estampas ou imagens de plano de fundo (exceto para áreas de destaque, como no caso do "carrossel"). Há, de fato, poucas imagens ou texto inerentes ao layout, o que permite que o foco permaneça nas peças, em suas cores, formatos e características. Todos os sites analisados são muito bem planejados com relação ao balanço entre clareza visual e apresentação dos itens ou produtos de cada marca.

\subsection{Tipos de texto}

Em concordância com os aspectos relacionados às cores, o uso de texto nos sites das marcas analisadas está restrito, na maioria das páginas, a apenas identificar o nome de uma peça ou trazer uma breve descrição sobre um produto. Em outras palavras, com exceção óbvia das páginas de notícia ou destinadas a contar a história ou os princípios da marca, os layouts apresentam pouquíssimo uso de textos, o que, novamente, demonstra que o foco deve permanecer nos itens sendo exibidos ou ofertados. 


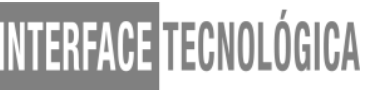

Por conseguinte, algo bastante observável em 9 das 10 marcas é que estas preferem letras mais minimalistas, sem serifa, ocasionalmente apenas alternando o tamanho e os estilos de regular para negrito (mas sem alterar a própria fonte). Apenas o site da marca Hèrmes mistura, em algumas páginas, uma fonte com serifa discreta (figura 4).

Figura 4. Páginas dos sites da Chanel e da Hèrmes, em relação à tipografia utilizada.
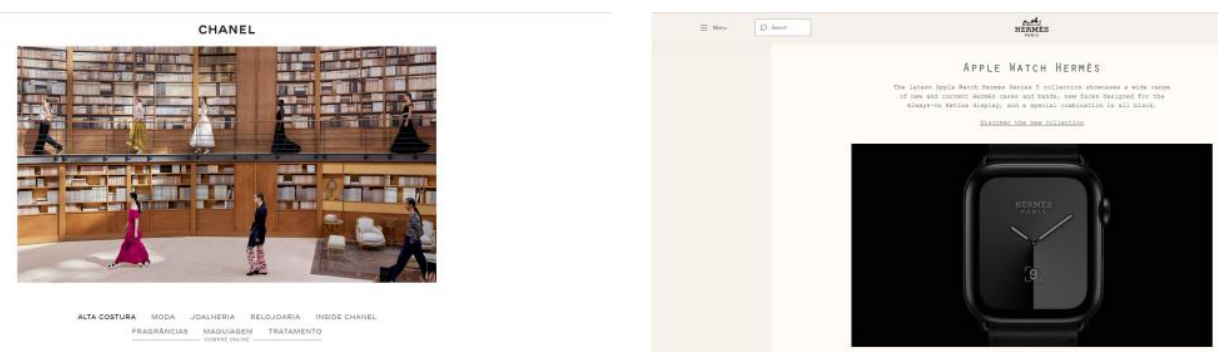

Fonte: capturas de tela realizadas pelos autores.

Com relação às cores dos textos, todas as informações são exibidas em preto e, em algumas áreas com fundo escuro (como em rodapés), o texto define-se em branco. Não se percebe, afinal, o uso de textos coloridos ou com efeitos artísticos, tais como sombras ou brilhos. A tendência, nesse caso, é manter os textos mais minimalistas possível.

\section{CONSIDERAÇÕES FINAIS}

Existem inúmeras possibilidades que podem ser utilizadas para o desenvolvimento de um layout de página da web. Geometrias, imagens, vídeos, cores e formas tipográficas podem ser combinadas em um número sem fim de maneiras para alcançar o resultado que se queira. No entanto, como observado a partir de autores, tais como Cardoso (2013), Gomes Filho (2009), Lupton e Phillips (2015), Mestriner (2005) e Wollner (apud STOLARSKI, 2005), o design é muito mais do que apenas cuidar da beleza; trata-se de um planejamento minucioso quanto à facilidade de utilização, interatividade e conexão com o público de interesse, o que não deixa de envolver, obviamente, aspectos estéticos inerentes ao belo.

Logo, voltando-se para a moda, o design de página deve ser projetado para que, ao acessar o site de uma marca que trabalha neste segmento, o usuário não tenha a menor dúvida de que se trata de uma empresa do mundo fashion. Isso fica muito claro nas análises realizadas entre os 10 sites das marcas de moda mais valiosas do mundo: todas possuem, em 


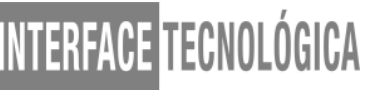

seus portais, um visual muito minimalista, cujo foco encontra-se, sobretudo, na exposição dos itens de vestuário. Há, neste sentido, poucos elementos de layout propriamente; com fundos em cores sólidas, em sua maioria branco, e poucos textos (com fontes sem serifas), na maioria em preto, o destaque permanece nas belíssimas imagens que realçam as roupas, acessórios e coleções de cada marca. Afinal, se o segmento da moda produz, frequentemente, novos modelos e coleções, então este, definitivamente, é o foco em cada página projetada.

A constatação, a partir destas análises, é que a estrutura de layout não precisa ser carregada de elementos visuais, efeitos ou outros recursos para ser bela; uma página em fundo branco não significa que é pobre visualmente; quanto mais o foco é direcionado ao conteúdo (e menos à estrutura), mais a marca é capaz de apresentar aquilo que realmente importa: seus produtos, novidades, ofertas e benefícios. Isso ajuda, inclusive, na responsividade dos sites, já que, notadamente, milhares de pessoas atualmente acessam a Internet por meio de seus dispositivos móveis, em adicional ou no lugar dos computadores fixos e monitores maiores.

Mais conteúdo, mais clareza visual e muito mais ênfase na marca e em suas ofertas são os principais pontos para o bom desenvolvimento de um site de moda, o que, certamente, pode ser um caminho muito vantajoso e inspirar inúmeras outras marcas menores deste e de outros segmentos a projetarem seus layouts de página.

\section{REFERÊNCIAS}

AMBROSE, Gavin; HARRIS, Paul. Fundamentos de design criativo. 2ed. Porto Alegre: Bookman, 2012.

BRANDZ Top Global Brands. Kantar Millward Brown, 2019. Disponível em: < http://www.millwardbrown.com/brandz/rankings-and-reports/top-global-brands/2019 >. Acesso em: 8 set. 2019.

CARDOSO, Rafael. Design para um mundo complexo. São Paulo: Cosac Naify, 2013.

DEL VECHIO, Gustavo. Design Gráfico com Adobe Illustrator: um guia para profissionais e estudantes de artes e design. Rio de Janeiro: Elsevier, 2012.

Marcas organizacionais e a agregação de valor institucional por

meio do investimento em ações sociais alternativas. Dissertação de Doutorado. São Bernardo do Campo: Universidade Metodista de São Paulo, 2015.

GOMES FILHO, João. Gestalt do Objeto: sistema de leitura visual da forma. 9ed. São Paulo: Escrituras Editora, 2009. 
GUIMARÃES, Luciano. A cor como informação: a construção biofísica, linguística e cultural da simbologia das cores. 3ed. São Paulo: Annablue, 2004.

HELLER, Eva. A psicologia das cores: como as cores afetam a emoção e a razão. São Paulo: Gustavo Gilli, 2013.

LUPTON, Ellen; PHILLIPS, Jennifer C.; Novos fundamentos do design. 2ed. São Paulo: Cosac Naify, 2015.

MALZONE, Henrique V. Tipografia e layout: nada é por acaso. IN: DEL VECHIO, Gustavo. Design Gráfico com Adobe Illustrator: um guia para profissionais e estudantes de artes e design. Rio de Janeiro: Elsevier, 2012.

MESTRINER, Fabio. Design de embalagem: curso avançado. 2 ed. São Paulo: Pearson Prentice Hall, 2005.

OLIVEIRA, Sandra R. Moda também é texto. São Paulo: Edições Rosari, 2007.

STOLARSKI, André. Alexandre Wollner e a formação do design moderno no Brasil: depoimento sobre o design visual brasileiro. São Paulo: Cosac Naify, 2005. 